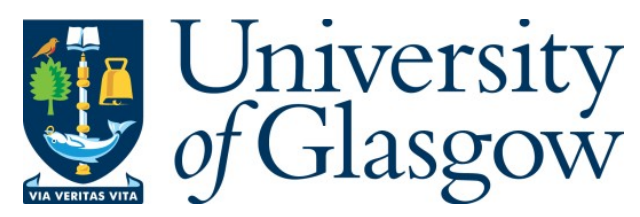

Gherghina, S., Plopeanu, A.-P. and Necula, C.-V. (2020) The impact of socio-cultural integration on return intentions: evidence from a survey on Romanian migrants. Journal of Immigrant and Refugee Studies, 18(4), pp. 515-528.

(doi: $10.1080 / 15562948.2020 .1735599)$

This is the Author Accepted Manuscript.

There may be differences between this version and the published version. You are advised to consult the publisher's version if you wish to cite from it.

https://eprints.gla.ac.uk/211157/

Deposited on: 26 February 2020

Enlighten - Research publications by members of the University of Glasgow http://eprints.gla.ac.uk 


\title{
The Impact of Socio-Cultural Integration on Return Intentions: Evidence from a Survey on Romanian Migrants
}

\author{
Sergiu Gherghina \\ Department of Politics \\ University of Glasgow \\ Aurelian-Petruș Plopeanu \\ Department of Interdisciplinary Research - Humanities and Social Sciences \\ Alexandru Ioan Cuza University of Iași \\ Constantin-Valer Necula \\ Andrei Șaguna Faculty of Orthodox Theology \\ Lucian Blaga University of Sibiu
}

\begin{abstract}
This article analyzes the impact of socio-cultural integration on migrants' intention to return to their country of origin. It distinguishes between the potential effects of inter-ethnic relations, language proficiency and perception of discrimination as components of integration. It uses individual-level data collected through an original survey among Romanian migrants in January 2018. It aims to test the effects of socio-cultural integration against those of alternative explanations provided in the literature. The findings indicate that the perception of discrimination, assessment of public institutions' performance and belonging feelings are important predictors for return intentions.
\end{abstract}

Keywords: migrants, return, integration, discrimination, Romania

\section{Introduction}

The intention of migrants to return to their country of origin is the result of integration in the country of residence, transnationalism (attachment to the country of origin) and the interaction between these two processes (Carling and Pettersen, 2014). Integration is used as an umbrella concept that includes a broad array of factors ranging from how migrants adapt to the socio-economic conditions of their new "home" to how they feel in the host society. Most studies seeking to understand the effects of integration on the intention to return has focused on work, family and socio-cultural integration.

Work possibilities, skills and the degree of labor market integration in the country of residence can make a difference. Employment on a continuous basis deters the intention to return, while unemployment, occupations of jobs below migrants' capabilities or the status of dependent worker can have the opposite effect (Constant and Massey, 2002; Olofsson and Malmberg, 2011; Model, 2016; Bettin, Cela and Fokkema, 2018; Bonifazi and Paparusso, 2019). The partnership formation, bi-national marriages, reunited families or 
childbirth (Koelet and Valk, 2014; Bonifazi and Paparusso, 2019) can negatively influence the intention to return. A similar effect can be observed for the partnership dissolution between migrants and their partners in their country of origin (Bettin, Cela and Fokkema, 2018). The socio-cultural integration refers to language proficiency (Anniste and Tammaru, 2014; Bilgili and Siegel, 2017), informal social contacts with natives (Snel, Engbersen and Leerkes, 2006; Anniste and Tammaru, 2014), orientation towards migrants' own culture (Bilgili and Siegel, 2017), endorsement of society's prevailing moral standards and values in the country of residence (Snel, Engbersen and Leerkes, 2006). So far, these components of social-cultural integration have been treated in isolation without a comparative assessment of their potential impact on the intention to return.

This article addresses this research gap and contributes to the existing literature in two ways. First, we offer a conceptual framework that distinguishes among the motives related to socio-cultural integration. Instead of treating the socio-cultural integration as a homogenous concept, we differentiate between three components - inter-ethnic contacts, language proficiency and the perception of discrimination - to evaluate their explanatory power. This framework serves as a tool to understand how migrants see their integration in the society of residence and the extent to which the three components shape their intention to leave. We intend to deliver a framework that is generally applicable to studies of migrants' adaptation and could be used by further research.

Second, we use this framework to empirically analyze return migration intentions among Romanian migrants. Romania is one of the top emigration countries in Europe and research on prospects for return migration is an important contribution to the field. The effect of the three components of socio-cultural integration is empirically tested against alternative explanations such as the perceived benefits of migration, length of stay in the host country and belonging. The empirical analysis uses an original dataset including individual-level data. This was collected through an online survey in January 2018 on a convenience sample of 1,839 first-generation Romanian migrants. The respondents are current migrants who live in another country than Romania. The integration is a crucial component of migration and a close investigation of its effects on intentions to return would advance existing knowledge in the field.

The remainder of this article proceeds as follows. The first section reviews the literature on intentions to return and formulates four testable hypotheses corresponding 
to different components of the socio-cultural integration. Next, we briefly describe the case selection, variable measurement and methodology. The third section includes the empirical findings, while the article concludes with the major implications of this study and avenues for further research.

\section{Socio-cultural integration and its potential effects}

A series of theories proposed different approaches and key determinants to understand intentions to return. The economic theories consider migration as the result of a rational choice in which migrants are driven by individual utilitarian benefits and calculated strategies. They decide to return when their earnings are less than they used to be. The structural approach to returning migration adds a community perspective to individual economic thinking. It focuses more on explaining what happens to the migrants after their return and emphasizes that this decision is a matter of context in the country of origin. Transnationalism explains the phenomenon of return as a mixture of transnational identities and mobility. Migrants do not have identities anchored exclusively in the country of origin or of residence and opt for a more inclusive approach that is shaped by increased mobility. All these theories successfully cover important bits and pieces of the potential drivers: financial well-being, institutional context, ties with communities in the country of origin and hybrid identities; for an extensive critique of their shortcomings, see Cassarino (2004).

The socio-cultural integration refers to migrants' ability to become part of the host society (Gijsberts and Dagevos, 2007). It covers several elements such as the type of contacts and networks developed in the host society, attitudes towards the cultural elements in the host society, knowledge of the language, or the sense of belonging to the host society (Snel, Engbersen and Leerkes, 2006; Gijsberts and Dagevos, 2007). The effects of socio-cultural integration have been often reduced to one or two of these components. This article focuses on the most common components of social-cultural integration and proposes several arguments according to which inter-ethnic contacts, language proficiency and the perception of discrimination may be important determinants for the intention of migrants to return to their country of origin.

The first argument refers to the quality of inter-ethnic contacts between the majority population from the host country and groups of migrants. The better these 
contacts are, the more likely is for the migrants to continue living in that community. Conversely, poor relations with the locals can shape the intention to return to their country of origin. The main reasoning behind this expectation is embedded in the social network theory. Through the nature of their mobility, migrants have access to and construct networks with different types of people in different social contexts (Ryan, 2011). We refer here to a particular social network - the one formed in the post-migration phase, with the majority population form the community where migrants live. In discussing types of social networks, Putnam (2000) differentiates between bonding, i.e. with similar people, and bridging ties, i.e. with people who are different. He explains that the two have different purposes: the former is useful to create a feeling of safety and to ensure a pleasant environment for those belonging to the in-group, while the latter is important to get more perspectives on things and to advance a broader understanding about how society works. The two are not mutually exclusive since people can create bonding relations on some dimensions and bridging on others.

In terms of migration, the closed bonding networks taken to an extreme and excluding contacts with those who are different can be conducive to the isolation of the migrants through the creation of ethnic enclaves (Crowley and Hickman, 2008). In general, the bridging networks of migrants are associated with their integration (Jacobs and Tillie, 2004; Nannestad, Lind Haase Svendsen and Tinggaard Svendsen, 2008; Ryan et al., 2008). The ability to create networks with local people reflects the migrants' community involvement and an orientation towards something else than their country of origin. Access to networks is difficult since it requires extensive voluntary action from those who initiate the contact and consent of the other members. Equally important, these networks are based on long-lasting interpersonal relations and an exchange of mutually valuable items between their members (Cassarino, 2004). Migrants can use various channels through which contacts with locals can be established and maintained. One such example is, in the case of female migrants who do so through school and childcare (Ryan et al., 2009; White, 2010).

The case of the second-generation Caribbean migrants in the UK is an example of impediments to bridging networks. These migrants who did not consider themselves fully integrated within the British society because of their different ethnicity, culture and values were more likely to return to their homeland (Reynolds, 2008). However, good relations 
with the locals are not granted not even in the case of ethnic similarities. Earlier research showed how ethnic similarity with natives offers advantages to migrants in search of housing, educational opportunities, understanding the values and functioning of the host society and access to better jobs (Cook-Martín and Viladrich, 2009). Traditional migrants are appealing to employers because of their willingness to put up with low wages and poorer working conditions compared to the natives. This usually happens because they often lack the skills or qualifications to compete for the same positions, and have different expectations and knowledge regarding their legal rights. Many of these are levelled out in the case of migrants with cultural affinity, they may end up competing with natives for professional and better-paid jobs (Cook-Martín and Viladrich, 2009), and this could result in tensions within the local communities.

The social networks created by migrants with the locals are systems of social relations that reflect upon their involvement in the community in which they live. Good and strong relations provide an appropriate setting in which migrants can develop a sense of belonging. They can feel accepted by the host society in spite of differences. In this sense, the gap between the two worlds - and homes - narrows and reduces the return intention to the country of origin. Poor relations mean the presence of opposite features to what described above and migrants do not develop a sense of belonging to the local community. Migrants could easily readapt in their country of origin if they were not at all integrated into the host societies, despite different factors of dissuasion. "Negative social conditions in the immigration context create integration problems as well as failure in sense of belonging to the country of immigration" (Kunuroglu, van de Vijver and Yagmur, 2016, p. 9). Adversarial situation and isolation make them see their migration experience as being temporary and have few incentives to continue in that community. As such, their motivation to return is greater.

Our second argument is that poor knowledge of the language spoken in the host country can have a similar effect to the one described for the relations between migrants and locals. Language proficiency is considered a specific form of human capital and, for migrants, better work performance and integration in the host society can be achieved if they learn the language of that country (Carliner, 2000; Chiswick and Miller, 2007). Research shows how good knowledge of the host country's language has an important role for the future integration (Dustmann and van Soest, 2002; van Tubergen, Maas and 
Flap, 2004; Gundel and Peters, 2008). Language proficiency is an asset for those who wish to continue their life in the countries of residence. Once migrants are familiar with the host country's language, they can interact more and better with the locals (Martinovic, Tubergen and Maas, 2009, p. 872), have better hiring opportunities with the possibilities to perform different tasks which may increase their productivity and could earn better (Chiswick, 1998, p. 267).

Language proficiency improves the prospects of migrants' children careers (Heath, Rothon and Kilpi, 2008), which may influence the decision to remain for longer periods. If migrants have poor knowledge of the language, then the costs of social and labor market integration are sometimes too high. The likelihood to stay in the host country is positively influenced by the proficiency in speaking the host country's language (Hinks and Davies, 2015). The return migrants are often characterized by a low capacity to acquire linguistic proficiency (Isphording, 2015). There are several reasons behind this characteristic, which can work alone or in conjunction. One of them is the temporary stay that is planned prior to migration. Migrants are aware that the time spent in the country of residence is limited and thus have no incentives to learn it. Another reason is the lack of interaction with natives, with some of the migrants interacting exclusively with their nationals in the country of residence. Another reason can be the poor education and limited access to learning resources of those who migrate. Many of them occupy low-profile jobs, which often require a great deal of time and does not pay well enough to grant the possibility to learn in an education facility the language of the country of residence.

Earlier studies show that in the case of immigrants in the UK, the ability to express themselves fluently in English increases their likelihood to find a job by approximately $20 \%$ and the obtained earnings by almost the same percentage (Dustmann and Fabbri, 2003). As such, insufficient knowledge of the language can increase the risks of social marginalization and economic and professional segregation.

The third argument is that the perception of discrimination in the host country may influence the intention of migrants to return (Chabé-Ferret, Machado and Wahba, 2018). Discrimination is about behavior, an action that is taken against a person or a group; this is different from prejudices and stereotypes, which are attitudes against persons or groups and can form the grounds for a discriminatory action (Stephan et al., 1998; Leavey, Sembhi and Livingston, 2004; Quillian, 2006). Discrimination can take a variety of forms that range 
from verbal abuse or feeling less valued as a human being to unfair practices, bias and harassment (Szczepura et al., 2004; Agudelo-Suárez et al., 2009). Earlier studies showed that discrimination can be either real or perceived. The existence of real discrimination is difficult to document since it is an attitude that forms the basis for particular decisions and behaviors. The latter can be striking and indicates a discriminatory behavior but such manifestations are isolated in contemporary societies, especially when laws prohibit them. Under these circumstances, discrimination is better reflected through perceptions, i.e. the subjective understanding of those who are its victims. This is the reason for which perceived discrimination is used and broadly accepted as an indicator for the unequal access to resources based on the different ethnicity, race or skin color (Dion and Kawakami, 1996; Verkuyten, 1998; Broman, Mavaddat and Hsu, 2000).

Discrimination is part of the migration experience together with other elements that make the integration of migrants difficult such as the differences in the cultural values, beliefs and practices, or hostility (Stephan et al., 1998). Earlier research illustrates the difficulties for migrants to deal with other labor market rules and lower opportunities for employment and career advancement in comparison with the native workers due to discrimination (Dustmann, 1997). The discrimination often derives from perceptions in the host society regarding specific phenotypical and cultural characteristics (Portes, 2001). Discrimination appears to be an important hindrance to a full integration of migrants, increasing the perceived attitudes of marginalization (Jasinskaja-Lahti et al., 2003; Luque et al., 2006; Roytburd and Friedlander, 2008). Migrants could have problems to find new or better jobs when the host society is extremely ethnically homogenous (Portes and Rumbaut, 2001; Behtoui, 2007); these are situations in which discrimination is likely to occur and to play important roles.

Previous research shows how discrimination is a societal feature with negative effects towards migrants, transmitting the information that the boundaries of the host society are impregnable (Bakker, van der Zee and van Oudenhoven, 2006). One of the most common consequences is psychological and affects their mental well-being. For example, a survey conducted on Mexican migrants in the US revealed that the perception of discrimination has a relevant impact on their integration and mental health (Finch, Kolody and Vega, 2000). Similarly, a study of African American young people in the US reveal how perceived discrimination induces depression and stress (Brody et al., 2006) 
Discrimination towards migrants suppresses both their beliefs and the feeling that they could be part of the host society, increases the tensions between majority and minorities and demotivates the latter to integrate. Countries that implement nondiscriminatory migration policies to encourage the economic, political and social participation of migrants are likely to positively influence their decision to continue living in the host countries (Paparusso and Ambrosetti, 2017). Other findings confirm the positive influences of discrimination, racism or xenophobia on returning to the homeland and an extremely low sense of belonging to the values of the host societies (Cohen, 1996; Bolognani, 2007; Kunuroglu, van de Vijver and Yagmur, 2016). Tartakovsky (2012, p. 97) summarizes this as follows:

Immigrants, who feel accepted by the host society, i.e. enjoy sufficient social support and suffer little discrimination, are more likely to choose the integration or assimilation acculturation strategies and remain in the host country. Immigrants who feel rejected by the host society are more likely to choose the separation or marginalization acculturation strategies and have a stronger desire to leave the country.

Following these arguments, we expect that the migrants' intention to return to the country of origin can be influenced by':

H1: Poor relationships with the locals

$\mathrm{H} 2$ : Poor knowledge of the language in the host country

$\mathrm{H} 3$ : The perception of discrimination

\section{Control variables}

The explanatory power of the three main effects captured by the hypotheses will be empirically tested against the usual determinants emphasized by previous research. The point that we try to make is not that socio-cultural Integration is the only one that matters for the intention of migrants to return, but it is one relevant cause that was ignored. The

\footnotetext{
${ }^{1}$ One could make an argument in favour of reverse causality for the first two hypotheses. Migrants do not pursue good relationships with the locals and are not interested in learning the language of the host country because they plan to return to their country of origin. That is likely to occur in very specific circumstances: motivations strictly related to the financial benefits and a job that allows them to communicate only in their mother tongue. In reality, although migrants envisage a short stay, they still cultivate social relations and seek to maximize their job opportunities. Using our data, we tested empirically whether migrants who plan a shorter period of stay have poorer relationship with the locals and language knowledge. The results do not reveal any relevant correlation between these variables.
} 
alternative explanations are used as controls: the perception of public institutions' performance, length of stay, belonging, age and education.

Public institutions play a major part in contemporary societies. They regulate and control a series of public goods or a broad array of crucial resources for the well-being of individuals such as health, safety, security, education etc. The access to these goods can determine migration but also return intentions. The latter may be influenced by specific problems related to the functioning of public institutions in the country of residence. Migrants usually leave when the costs associated with their stay in the host country are too high compared to the benefits. This type of reasoning involves a comparison between what the migrants could get from the two countries - of origin and residence - in terms of service and good delivery. Using an analogy with what happens in economic terms (Hinks and Davies, 2015), the return intentions are low when the difference between the institutional performance in the country of residence and that of origin is high. In other words, when migrants "get more" access to services and goods in the country of residence, they are unlikely to return.

A longer stay abroad, which can be seen as a predictor for assimilation, is likely to negatively influence the return intentions (Makina, 2012; Hinks and Davies, 2015; Bonifazi and Paparusso, 2019). More time spent in the host societies can have a positive impact on the intention to return since the migrants may have acquired financial capital to the expected or calculated level. The issue of belonging can be an important driver for the intention to return to the country of origin. Earlier studies reveal how the existence (or lack) of an identity related to the country of origin or of residence can push migrants to return (Leavey, Sembhi and Livingston, 2004; Wessendorf, 2007). Migrants who do not feel welcome in the country of residence or those who feel strong emotional attachment to their country of origin are expected to be more likely to return. Paparusso and Ambrosetti (2017) point out that those migrants who left their country of origin at younger ages, is highly integrated into the host societies compared with the older ones, due to educational, cultural and socio-economic accumulations, are more likely to stay in the country of residence. $^{2}$

\footnotetext{
${ }^{2}$ We controlled for a series of other variables that were mentioned as potential drivers for return intentions by previous research, e.g. job status, the medium of residence, gender, planned duration of stay. These variables were either highly correlated with the ones we use in our analysis or do not find empirical support. Consequently, they are not reported in the findings.
} 


\section{Data and Methodology}

To empirically test these effects, we use individual-level data from an original web survey conducted among Romanian migrants in January 2018. The Romanian migrants were selected as the subject of this study due to their high mobility across a large number of countries in the world. Official statistics are not available in many countries since formal registration is not required, especially in the EU Member States. According to the UN estimates, in 20173.6 million Romanians were living abroad (UN Report 2017), thus making the fourth largest diaspora in Europe after the UK, Poland and Germany - all countries with a much larger population. The Eurostat data and 2011 census at national level indicate that approximately 20 million Romanians live in the country. The preferred migration destinations are Italy, Spain, UK, Germany, France and the United States (Anghel, 2013). This is reflected also in our sample of respondents where almost $70 \%$ of those who filled in the online survey live in one of these six countries. The remaining $30 \%$ live in other 38 countries around the world as far as Australia, Japan, New Zealand, Singapore or Tonga.

In the absence of official reliable statistics regarding the Romanian migrants, we cannot know the features of the entire population and thus we could not use probability representative sampling. Besides, we aimed to include also the irregular migrants. We used a convenience sample in which the respondents were neither pre-selected nor part of a pool of available individuals. We distributed the online survey mostly through messages on Facebook groups or discussion forums of Romanians living abroad, and by e-mails sent to representatives of Romanian associations and organizations. While we are aware that such a sampling strategy confines the findings presented in this article to our respondents, we consider them quite informative and with important implications for the study of return migration.

The dataset consists of 1,839 answers collected from first-generation migrants of Romanian origin. Although the survey had no explicit age limit (e.g. under 18), all respondents were between 19 and 71 years old with no clear bias in terms of age and education. Some online surveys are biased towards the young or old respondents due to their skills in using technology or time they can allocate, but this was not the case here. In general, there is great variation in the respondents' profile due to the different patterns of migration to these countries. The profile varies across the independent and control 
variables of this study and in terms of other sociodemographic variables (e.g. gender, occupation, area of origin and residence).

The dependent variable is measured on an 11-point ordinal scale as the answer to the following question: "How likely is it for you to return to live in Romania in the following two years?". The respondents were asked to choose between different values on a scale ranging between o (very low likelihood) and 10 (very high likelihood). The relationship with locals ( $\left.\mathrm{H}_{1}\right)$ are measured on a five-point ordinal scale based on the following question: "How would you describe your relationships with those from the locality in which you live at the moment (we refer in particular to those born in the host country)?". The possible answers range between "very poor" (coded 1) and "very good" (coded 5). The language proficiency $\left(\mathrm{H}_{2}\right)$ is measured through the answers provided to the following question "How well do you speak at the moment the language of the country in which you live?". The answers are coded on a five-point ordinal scale between "very little" (1) and "very well" (5). The perception of discrimination $\left(\mathrm{H}_{3}\right)$ is operationalized also on a five-point ordinal scale based on the questions "During your stay in this country, did you feel discriminated against?". The possible answers range between "not at all" (1) to "very much" (5). The issue of discrimination is usually different for women and ethnic minorities. The survey includes the gender of respondents and we checked the extent to which women migrants feel discriminated more than men migrants. There are very small differences between the groups, which do not influence the final analysis. The questionnaire did not ask about the ethnic background of respondents. Initially, it had a question on this but during the pilot study - before the fielding of the survey - many respondents skipped the question.

Turning to controls, the better performance of public institutions variable is an index computed as follows. Respondents were asked to assess whether several public institutions work better in the country in which they live compared to how they work in Romania. These institutions cover several spheres of society: the educational system (schools, kindergartens), the health system, the local authorities, other public institutions such as the Police, central authorities such as the Parliament or the government. In their assessment of how institutions work, the respondents can have a broad understanding ranging from the effectiveness and efficiency of institutional functioning to the access individuals have to them; the latter is particularly important in Romania where access to 
public institutions is often problematic. All respondents who answer that these institutions work better or much better were coded 1, while those who assess that they work the same or worse were coded o. We merge the "same" and "worse" options based on findings from the literature that indicate that when things are equal in the country of origin or abroad, people tend to return because they assess the costs as being too high. The length of stay is measured through the answers to the following question "for how long do you live in this country (please mention the total period, not the one of interrupted stay)?". The possible answers were "less than six months" (coded 1), "6 months to one year" (2), "one to three years" (3), "three to six years" (4) and "more than six years" (5).

Belonging is measured through the question "How emotionally attached do you feel to the country in which you currently live", with possible answers ranging on a fivepoint ordinal scale between "not at all" (1) to "very much" (5). The country was chosen as the point of reference to be consistent with what captured by the other questions; we also asked respondents about attachment to the region and locality in which they live and both correlate highly to the country attachment. Age is measured though the year of birth, while education measured as the highest degree completed is coded on an ordinal scale that ranges between "primary school” (1) and "post-graduate studies" (7). For all the variables, the "DK/NA" answers are treated as missing values and excluded from the analysis.

The empirical analysis from the following section starts with a general discussion about the distribution of preferences for return. It is followed by inferential statistics that include bivariate correlations and ordered logistic regression to test the hypotheses and controls. The statistical models include the entire sample and we do not run country-level models. We tested for the effect of the country of residence on the likelihood of return intensions by using country dummies. The results showed no sizeable effect and thus we dropped them from the analysis. Before running the regression, we tested for multicollinearity and the results indicate no highly correlated predictors, i.e. the highest value is around 0.35 . There are theoretical reasons to expect a correlation between some of the independent variables. For example, the belonging to the country of residence and perception of discrimination can be in theory related, as a number of previous studies show (see the theoretical section above). In practice, at least for the results of our survey, this does not happen. The independent variables do not correlate at a level that may raise problems in the multivariate regression analysis. 


\section{Discrimination, Costs and Belonging}

Figure 1 includes a quantile plot that depicts on the vertical axis the return intention to the country of origin and on the horizontal axis the fraction of the data. The distribution indicates that a large share of the respondents do not have return intentions soon, with roughly half of the migrants choosing the very low likelihood end of the scale. In spite of this preponderance, there is considerable variation in the return intention. For example, the medium likelihood to return is the third popular option, while the very high likelihood to return exceeds several other choices. There is only a low possibility to have these two categories as biased choices due to the scale used. Earlier research showed that undecided people choose the middle option. They can do the same when the scaler is set to the middle point. We used a dynamic scaler in the online survey which did not record the values when people do not move it. Thus, even for a middle value, they have to make efforts and position the slider in that point.

Figure 1: The Distribution of Respondents according to Return Intention

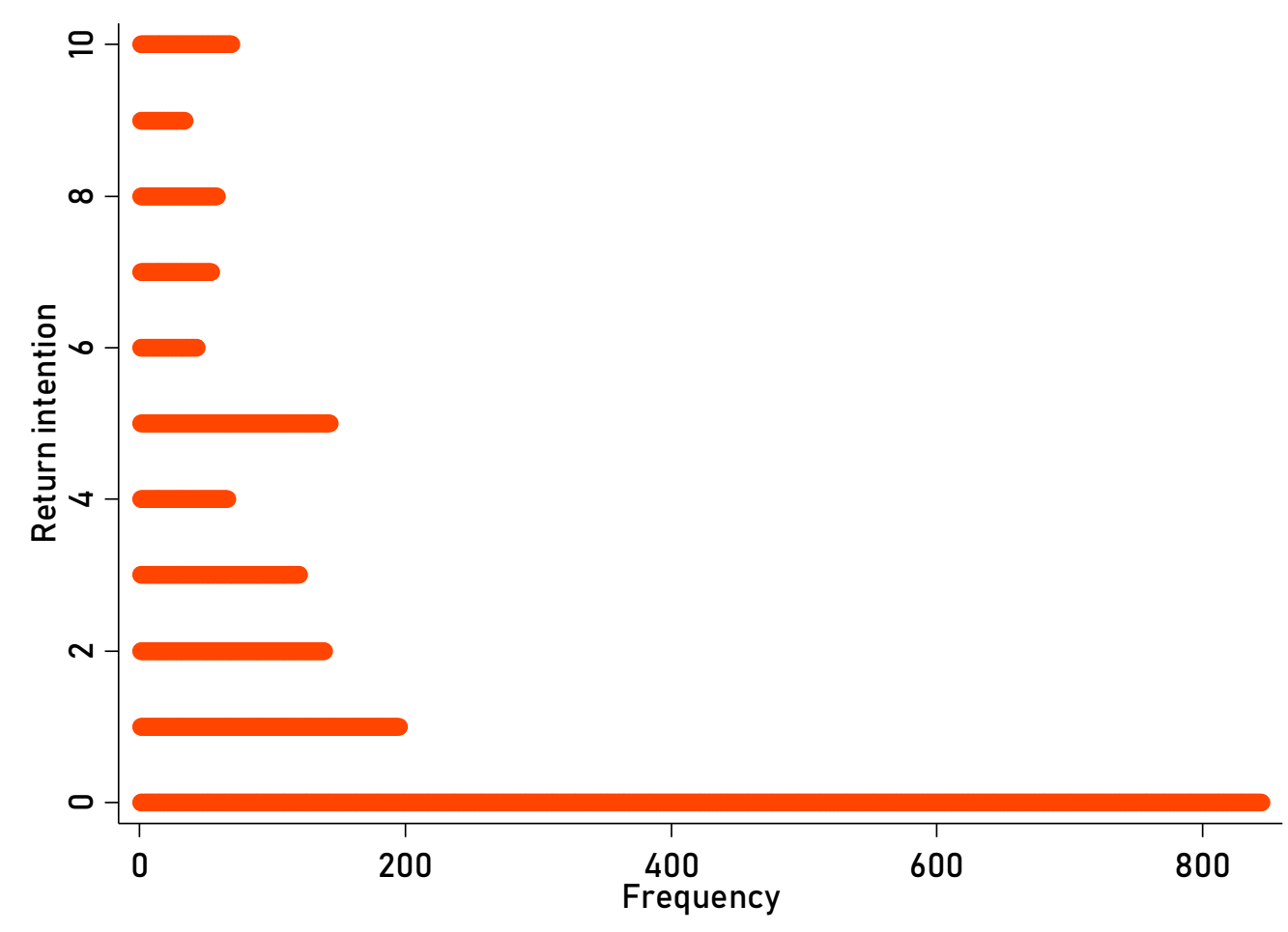

This figure allows the formulation of two general observations. First, there is a relevant difference between the preferences of Romanian migrants of returning to their country of origin. Second, the majority of respondents do not have return intentions in the near 
future, with six out of 10 indicating very low likelihood to do so (values 0 and 1 on the scale). This is a reality for many years and statistics in 2009 reveal a very low proportion of Romanian migrants returning to their country of origin and deciding to remain (Anon 2009). This happens due to the pessimistic forecasts regarding the domestic labor market, the opportunities to find better-paid jobs and the chances to build start-ups (Ferri and Rainero, 2010). Many Romanian highly-skilled migrants successfully integrated into host societies and brought benefits to the socio-economic situation in Romania (Moroşanu 2013, p. 361). Equally important, there is a low quality of life in many Romanian cities and villages compared to that in the countries of residence and the EU average (Burja and Burja, 2014). Such a situation limits the incentives for return intentions among those Romanian migrants who come from areas that have little to offer in terms of everyday life.

Let us now turn to the bivariate relationship and observe to what extent the variables included in the hypotheses and the controls correlate with the return intention to Romania. Table 1 includes the values of the correlation coefficients, which are nonparametric due to the ordinal nature of most variables. The direction, size of the coefficients and statistical significance at the 0.01 level provide empirical support for all three hypothesized relationships. The results indicate that poor relationships with the locals, poor knowledge of the language spoken in the host country and perceived discrimination are associated with a higher likelihood of return intentions. Among the three hypothesized effects, the perception of discrimination correlates the strongest (0.20).

The correlations between the controls and the dependent variable are statistically significant at the 0.01 level. Among them, the belonging correlates the highest with the return intention to Romania (-0.31): respondents who have low attachment to the host country indicate their desire to return. This is followed by the assessment of institutional performance (-0.19) and length of stay (-0.15) revealing that respondents who consider that institutions work as good in Romania as they do in the host country and those who stayed for a short time in the host country being more inclined to return.

Younger migrants have higher return intentions (0.14) and the same holds for those with lower levels of education (-0.06). These results refer to formal levels of education and a caveat must be explicitly addressed outlined. There is a difference between formal and real education. The formal education of migrants originates both in the institutional education carried out mostly in their country of origin and in online courses taken more 
recently to enhance their chances on the job market. The former have substance and are usually reflected in real education, while the latter are often degrees awarded in the exchange of large sums of money, without the benefit of real education. Our survey does not distinguish between these two forms of education but it is important to keep in mind these differences. The higher level of return intention among lower educated respondents is in line with earlier findings for Romanian migrants. For example, pupils and students have clear intentions to study abroad and approximately half of them are willing to return to the country of origin (Velciu and Grecu, 2017). In the case of medical doctors, nurses and midwives, the latter ones are more inclined to return than the rest (Roman and Goschin 2014). Also, the Eurofound Report (2012) shows that the low skilled Romanian migrants from Spain and Italy were more likely to return to the country of origin.

Table 1: Correlations and Ordered Logistic Regression

\begin{tabular}{|c|c|c|c|}
\hline & \multirow[t]{2}{*}{ Correlation } & \multicolumn{2}{|c|}{ Regression } \\
\hline & & Model 1 & Model 2 \\
\hline Relationships with locals & $-0.17 * *$ & $0.82 * *(0.05)$ & $0.94(0.07)$ \\
\hline Language proficiency & $-0.12 * *$ & $0.84 * *(0.04)$ & $0.93(0.05)$ \\
\hline Perceived discrimination & $0.20 * *$ & $1.31 * *(0.05)$ & $1.22 * *(0.05)$ \\
\hline Performance of public institutions & $-0.19 * *$ & & $0.78 * *(0.03)$ \\
\hline Length of stay & $-0.15 * *$ & & $1.01(0.06)$ \\
\hline Belonging & $-0.31 * *$ & & $0.61 * *(0.04)$ \\
\hline Age & $0.14^{* *}$ & & $1.02 * *(0.01)$ \\
\hline Education & $-0.06 * *$ & & $0.94(0.04)$ \\
\hline $\mathrm{N}$ & $1,537-1,765$ & 1,765 & 1,485 \\
\hline Pseudo $R^{2}$ & & 0.02 & 0.04 \\
\hline Log likelihood & & $-3155 \cdot 3851$ & -2546.1085 \\
\hline
\end{tabular}

Notes: The correlation coefficients are non-parametric (Spearman).

The $\mathrm{N}$ for correlations has a range instead of an integer value due to missing values for some variables.

The regression coefficients are odds-ratios (standard errors in parentheses)

$* * p<0.01 ; * p<0.05$ 
The results of the regression analysis are included in the same table and bring important nuances to the general picture. The interpretation of results is relative to the group of migrants who are very likely to return, i.e. the reference category. Model 1 includes all the three predictors from the hypothesized relationships and confirms the results of the correlations. Respondents who feel very much discriminated against are 1.31 more likely to return compared to those who feel no discrimination. Discrimination is the strongest predictor among the three effects hypothesized. Those migrants who have good relationships with locals and those with good language proficiency are less likely to return to the country of origin. All these effects are statistically significant at the 0.01 level.

Model 2, which includes the controls, has a higher value of the pseudo $\mathrm{R}^{2}$ that means that this model better fits the outcome data than the previous model. Since this is a pseudo $\mathrm{R}^{2}$, it does not say much about the explanatory power of the model and cannot be interpreted independently; it is useful to assess the two models predicting the same outcome on the same dataset. More substantial interpretation is possible when observing the values of the ORs reported in the table. In this model, two of the main predictors $\left(\mathrm{H}_{1}\right.$ and $\mathrm{H}_{2}$ ) lose their statistical significance. The effect of all three main predictors is weaker compared to Model 1. At the same time, three of the controls appear to have no effect on the return intention. Length of stay and education are weak predictors, without statistical significance. Age is significant, but with a very weak effect, making almost no difference if the migrants are young or old. Belonging and assessment of institutional performance are the strong predictors among the controls, their effect being matched by that of discrimination. These results match earlier findings. For instance, in the case of Romanian migrants in Madrid (Spain), the powerful feelings of belonging are often associated with a clear intention to return in the country of origin. "The immigrants who are most inclined to return to their country of origin are those who manifest a growing degree of loyalty to the people, place, and country of origin, and who simultaneously declare that they have little affection for the region that has received them" (Marcu, 2011, p. 10).

The empirical results lead to two major conclusions. First, there is an effect of the components of socio-cultural integration on the migrants' intention to return to their country of origin. This effect appears to be the strongest for perceived discrimination and somewhat weaker for the other two components. This observation holds when looking at the results of both statistical tests conducted. Symptomatic for the weaker impact of the 
relationship with locals and language proficiency is the fact that they lose statistical relevance in the second model of the regression analysis. These findings contradict earlier claims according to which there is a positive relationship between integration and the intention to return (Gundel and Peters, 2008; de Haas and Fokkema, 2011; Anniste and Tammaru, 2014). Better integration of the Romanian migrants at a social and cultural level translates into a greater willingness to stay in the country of residence. Those with lower social-cultural integration are more likely to intend to return, results which confirm the findings of earlier research (Bilgili and Siegel, 2017).

Second, the components of socio-cultural integration are as good or even better predictors than many of the usual explanations used in the literature. The statistical analysis reveals that the explanatory potential of perception of discrimination is matched by the perceived performance of public institutions and feelings of belonging. To some extent, the latter can be seen as a result of socio-cultural integration, especially when it is narrowed down to the feeling of belonging.

\section{Conclusions}

This article analyzed the extent to which three components of socio-cultural integration Inter-ethnic contacts, language proficiency and the perception of discrimination - may influence the intention of migrants to return to their country of origin. So far, this type of integration has been widely neglected as a potential explanation. Rather than considering its effect as the main explanation for return migration, we see it as a complementary to existing determinants highlighted in the literature. This is the reason for which we subjected them to empirical testing. The results indicate that the three components of integration have an effect on the migrants' intention to return to their country of origin. Among them, the perception of discrimination is more likely to have a stronger impact, even when compared to other explanations derived from economic or structural theories.

The implications of this study reach beyond its sample of respondents. The major theoretical advancement is the identification of a supplementary variable that can be used in the study of return migration. The socio-cultural integration is thus not only a consequence of various factors in the process of migration but can also be a cause. Its explanatory power can contribute to the general theoretical discussion about the importance of the environment, group and individual in migrants' departure from the host 
country. Another implication of our study is the conceptual and empirical separation between the components of socio-cultural integration. Our results show that these components have a different effect on return intentions and it is useful to treat them separately. On the same empirical note, the relevance of the three determinants illustrates that return migration has a plethora of causes. In this sense, a separate investigation of the economic or integration perspective provides only a limited account.

The findings of the current study could serve as a point of departure for future analyses in three possible ways. First, our analysis is limited to a group of first-generation migrants from Romania. The theoretical framework can be applied to different groups of migrants and explore the extent to which components of socio-cultural integration influence return intentions. These groups can be different in terms of their experience with migration, but also have different countries of origin and residence. Different groups of migrants could produce more robust results about the convergence or divergence of explanations. Second, one limitation of this analysis is the inability to identify ethnic minority members within the broader group of Romanian migrants. Such a feature is relevant especially concerning discrimination, which can be an issue both in the country of origin and in that of residence for some of the migrants belonging to ethnic minorities, e.g. Roma. The shortcoming can be addressed by future research through the development of a questionnaire aiming to capture ethnicity sensitively and substantially.

Third, although this study reveals important trends, it has the inherent limitations of quantitative analysis. This does not explore deeper the causal relationships, which can be achieved with qualitative analysis. Semi-structured interviews or focus groups can be conducted with Romanian migrants with a diverse profile in terms of the experience of migration, country of residence and socio-demographic characteristics. The added value of interviews and focus groups is that it allows migrants to freely express their thoughts without having to choose pre-established categories. Moreover, these qualitative techniques are a fruitful avenue to obtain unique evidence from migrants in the form of events or personal stories that are otherwise inaccessible. The interviews and focus groups can focus on how the intentions to return are formed - including how the limited prospects for return matter - and understand what determines these motivations from the perspective of social-cultural integration. 


\section{List of references:}

Agudelo-Suárez, A. et al. (2009) 'Discrimination, work and health in immigrant populations in Spain', Social Science \& Medicine, 68, pp. 1866-1874.

Anghel, R. (2013) Romanians in Western Europe: Migration, Status Dilemmas, and Transnational Connections. Lanham: Lexington Books.

Anniste, K. and Tammaru, T. (2014) 'Ethnic differences in integration levels and return migration intentions: A study of Estonian migrants in Finland', Demographic Research, 30, pp. 377-412.

Bakker, W., van der Zee, K. and van Oudenhoven, J. P. (2006) 'Personality and Dutch Emigrants' Reactions to Acculturation Strategies', Journal of Applied Social Psychology, 36(12), pp. 2864-2891.

Behtoui, A. (2007) 'The Distribution and Return of Social Capital: Evidence from Sweden', European Societies, 9(3), pp. 383-407.

Bettin, G., Cela, E. and Fokkema, T. (2018) 'Return intentions over the life course: Evidence on the effects of life events from a longitudinal sample of first-and secondgeneration Turkish migrants in Germany', Demographic Research, 39, pp. 1009-1038.

Bilgili, Ö. and Siegel, M. (2017) 'To return permanently or to return temporarily? Explaining migrants' intentions', Migration and Development, 6(1), pp. 14-32.

Bolognani, M. (2007) 'The Myth of Return: Dismissal, Survival or Revival? A Bradford Example of Transnationalism as a Political Instrument', Journal of Ethnic and Migration Studies, 33(1), pp. 59-76.

Bonifazi, C. and Paparusso, A. (2019) 'Remain or return home: The migration intentions of first-generation migrants in Italy', Population, Space and Place, 25(2), pp. 1-13.

Brody, G. H. et al. (2006) 'Perceived Discrimination and the Adjustment of African American Youths: A Five-Year Longitudinal Analysis with Contextual Moderation Effects', Child Development, 77(5), pp. 1170-1189.

Broman, C. L., Mavaddat, R. and Hsu, S.-Y. (2000) 'The Experience and Consequences of Perceived Racial Discrimination: A Study of African Americans', Journal of Black Psychology, 26(2), pp. 165-180.

Burja, C. and Burja, V. (2014) 'Sustainable Development of Rural Areas: A Challenge for Romania', Environmental Engineering and Management Journal, 13(8), pp. 1861-1871.

Carliner, G. (2000) 'The Language Ability of U.S. Immigrants: Assimilation and Cohort Effects ', International Migration Review, 34(1), pp. 158-182.

Carling, J. and Pettersen, S. V. (2014) 'Return Migration Intentions in the IntegrationTransnationalism Matrix', International Migration, 52(6), pp. 13-30.

Cassarino, J.-P. (2004) 'Theorising Return Migration: A Revisited Conceptual Approach to Return Migration', EUI Working Papers, (2), pp. 1-25.

Chabé-Ferret, B., Machado, J. and Wahba, J. (2018) 'Remigration intentions and migrants' behavior', Regional Science and Urban Economics, 68, pp. 56-72.

Chiswick, B. R. (1998) 'Hebrew language usage: Determinants and effects on earnings among immigrants in Israel', Journal of Population Economics, 11(2), pp. 253-271.

Chiswick, B. R. and Miller, P. W. (2007) The Economics of Language: International Analysis. London: Routledge.

Cohen, R. (ed.) (1996) Theories of migration. Cheltenham: Edward Elgar.

Constant, A. and Massey, D. S. (2002) 'Return Migration by German Guestworkers: Neoclassical versus New Economic Theories', International Migration, 40(4), pp. 538. 
Cook-Martín, D. and Viladrich, A. (2009) 'The Problem with Similarity: Ethnic-Affinity Migrants in Spain', Journal of Ethnic and Migration Studies, 35(1), pp. 151-170.

Crowley, H. and Hickman, M. J. (2008) 'Migration, postindustrialism and the globalized nation state: social capital and social cohesion re-examined', Ethnic and Racial Studies, 31(7), pp. 1222-1244.

Dion, K. L. and Kawakami, K. (1996) 'Ethnicity and perceived discrimination in Toronto: Another look at the personal/group discrimination discrepancy', Canadian Journal of Behavioural Science / Revue canadienne des sciences du comportement, 28(3), pp. 203-213.

Dustmann, C. (1997) 'Differences in the labor market behavior between temporary and permanent migrant women', Labour Economics, 4(1), pp. 29-46.

Dustmann, C. and Fabbri, F. (2003) 'Language Proficiency and Labour Market Performance of Immigrants in the UK', The Economic Journal, 113, pp. 695-717.

Dustmann, C. and van Soest, A. (2002) 'Language and the Earnings of Immigrants', ILR Review, 55(3), pp. 473-492.

Ferri, A. and Rainero, S. (2010) Survey of European Union and Return Migration Policies: the case of Romanian Migrants. Venice: Veneto Lavoro.

Finch, B. K., Kolody, B. and Vega, W. A. (2000) 'Perceived Discrimination and Depression among Mexican-Origin Adults in California', Journal of Health and Social Behavior, 41(3), pp. 295-313.

Gijsberts, M. and Dagevos, J. (2007) 'The Socio-cultural Integration of Ethnic Minorities in the Netherlands: Identifying Neighbourhood Effects on Multiple Integration Outcomes', Housing Studies, (5), pp. 805-831.

Gundel, S. and Peters, H. (2008) 'What determines the duration of stay of immigrants in Germany?: Evidence from a longitudinal duration analysis', International Journal of Social Economics, 35(11), pp. 769-782.

de Haas, H. and Fokkema, T. (2011) 'The effects of integration and transnational ties on international return migration intentions', Demographic Research, 25, pp. 755-782.

Heath, A. F., Rothon, C. and Kilpi, E. (2008) 'The Second Generation in Western Europe: Education, Unemployment, and Occupational Attainment', Annual Review of Sociology, 34(1), pp. 211-235.

Hinks, T. and Davies, S. (2015) 'Intentions to Return: Evidence from Romanian Migrants', World Bank Policy Research Working Papers, (7166).

Isphording, I. E. (2015) 'What drives the language proficiency of immigrants?', IZA World of Labor, 177. Available at: http://dx.doi.org/10.15185/izawol.177.

Jacobs, D. and Tillie, J. (2004) 'Introduction: social capital and political integration of migrants', Journal of Ethnic and Migration Studies, 30(3), pp. 419-427.

Jasinskaja-Lahti, I. et al. (2003) 'The interactive nature of acculturation: perceived discrimination, acculturation attitudes and stress among young ethnic repatriates in Finland, Israel and Germany', International Journal of Intercultural Relations, 27(1), pp. 79-97.

Koelet, S. and Valk, H. A. G. de (2014) 'European Liaisons? A Study on European bi-national Marriages in Belgium', Population, Space and Place, 20(2), pp. 110-125.

Kunuroglu, F., van de Vijver, F. and Yagmur, K. (2016) 'Return Migration', Online Readings in Psychology and Culture, 8(2), pp. 3-28.

Leavey, G., Sembhi, S. and Livingston, G. (2004) 'Older Irish migrants living in London: identity, loss and return', Journal of Ethnic and Migration Studies, 30(4), pp. 763-779. 
Luque, M. N. et al. (2006) 'Prejudice and attitudes of acculturation: Perspectives of autochthonous and immigrants', Psicothema, 18(2), pp. 187-193.

Makina, D. (2012) 'Determinants of return migration intentions: Evidence from Zimbabwean migrants living in South Africa', Development Southern Africa, 29(3), pp. 365-378.

Marcu, S. (2011) 'Romanian Migration to the Community of Madrid (Spain): Patterns of Mobility and Return', International Journal of Population Research, pp. 1-13.

Martinovic, B., Tubergen, F. van and Maas, I. (2009) 'Changes in immigrants' social integration during the stay in the host country: The case of non-western immigrants in the Netherlands', Social Science Research, 38(4), pp. 870-882.

Model, S. (2016) 'Falling Leaves Return To Their Roots': Taiwanese-Americans Consider Return Migration', Population, Space and Place, 22(8), pp. 781-806.

Nannestad, P., Lind Haase Svendsen, G. and Tinggaard Svendsen, G. (2008) 'Bridge Over Troubled Water? Migration and Social Capital', Journal of Ethnic and Migration Studies, 34(4), pp. 607-631.

Olofsson, J. and Malmberg, G. (2011) 'When Will the Russians Come? On Post-Soviet Immigration and Integration in Sweden', International Migration, 49(4), pp. 93-117.

Paparusso, A. and Ambrosetti, E. (2017) 'To Stay or to Return? Return Migration Intentions of Moroccans in Italy', International Migration, 55(6), pp. 137-155.

Portes, A. (2001) 'Introduction: the debates and significance of immigrant transnationalism', Global Networks, 1(3), pp. 181-193.

Portes, A. and Rumbaut, R. G. (2001) Legacies. Berkeley: University of California Press.

Putnam, R. D. (2000) Bowling alone: The collapse and revival of American community. New York: Simon \& Schuster.

Quillian, L. (2006) ‘New Approaches to Understanding Racial Prejudice and Discrimination', Annual Review of Sociology, 32, pp. 299-328.

Reynolds, T. (2008) 'Ties that bind: Families, social capital and Caribbean second generation return migration', Sussex Centre for Migration Research, (Working Paper 46), pp. 229.

Roytburd, L. and Friedlander, M. L. (2008) 'Predictors of Soviet Jewish refugees' acculturation: Differentiation of self and acculturative stress.', Cultural Diversity and Ethnic Minority Psychology, 14(1), pp. 67-74.

Ryan, L. et al. (2008) 'Social Networks, Social Support and Social Capital: The Experiences of Recent Polish Migrants in London', Sociology, 42(4), pp. 672-690.

Ryan, L. et al. (2009) 'Family Strategies and Transnational Migration: Recent Polish Migrants in London', Journal of Ethnic and Migration Studies, 35(1), pp. 61-77.

Ryan, L. (2011) 'Migrants' Social Networks and Weak Ties: Accessing Resources and Constructing Relationships Post-Migration', The Sociological Review, 59(4), pp. 707724.

Snel, E., Engbersen, G. and Leerkes, A. (2006) 'Transnational involvement and social integration', Global Networks, 6(3), pp. 285-308.

Stephan, W. et al. (1998) 'Prejudice toward Immigrants to Spain and Israel', Journal of CrossCultural Psychology, 29(4), pp. 559-576.

Szczepura, A. et al. (2004) Review of Occupational Health and Safety of Britain's Ethnic Minorities. Research 221. Report Available at: www.hse.gov.uk/research/rrpdf/rr221.pdf.

Tartakovsky, E. (2012) 'Factors affecting immigrants' acculturation intentions: A theoretical 
model and its assessment among adolescent immigrants from Russia and Ukraine in Israel', International Journal of Intercultural Relations, 36(1), pp. 83-99.

van Tubergen, F., Maas, I. and Flap, H. (2004) 'The Economic Incorporation of Immigrants in 18 Western Societies: Origin, Destination, and Community Effects', American Sociological Review, 69(5), pp. 704-727.

Velciu, M. and Grecu, L. (2017) 'Designing the Return Migration of Romanian Students', SEA - Practical Application of Science, 5(13), pp. 187-190.

Verkuyten, M. (1998) 'Perceived Discrimination and Self-Esteem Among Ethnic Minority Adolescents', The Journal of Social Psychology, 138(4), pp. 479-493.

Wessendorf, S. (2007) “"Roots Migrants": Transnationalism and "Return" among SecondGeneration Italians in Switzerland', Journal of Ethnic and Migration Studies, 33(7), pp. $1083-1102$.

White, A. (2010) Polish Families and Migration Since EU Accession. Bristol: Policy Press. 